\title{
A narrativa pós-moderna nos videoclipes da banda Disturbed: o deserto do real com sonhos de (uma) revolução (abortada)
}

\author{
Douglas Eraldo dos Santos ${ }^{\mathrm{i}}$ \\ Fabiana Piccinin ${ }^{\mathrm{ii}}$
}

\section{RESUMO}

Neste trabalho interpretamos duas narrativas em videoclipes da banda Disturbed, observando de que modo elas são impactadas pelas características do pós-modernismo, especialmente a complexa e paradoxal relação com o Real. Para tanto, consideramos as características do narrador pós-moderno e também a relevância dos videoclipes na cultura popular a fim de discutir como a paixão pelo real, a violência, o messianismo, a imobilidade social e a revolução são tratados nas respectivas narrativas.

Palavras-chave: Disturbed; Messianismo; Pós-modernismo; Real; videoclipes.

\begin{abstract}
In this work, we interpret two narratives in the music video of the band Disturbed by observing how they are impacted by the characteristics of postmodernism, especially the complex and paradoxical relationship with the Real. For this, we consider the characteristics of the postmodern narrator and also the relevance of the music videos for popular culture and we discuss how the passion for the real, violence, messianism, social immobility and revolution are portrayed in the corresponding narratives.
\end{abstract}

Keywords: Disturbed; Messianism; Music video; Postmodernism; Real.

\section{INTRODUÇÃO}

\footnotetext{
${ }^{i}$ Mestrando do Programa de Pós-Graduação em Letras da Universidade de Santa Cruz do Sul (UNISC). Bolsista pela Coordenação de Aperfeiçoamento de Pessoal de Nível Superior (CAPES). ORCID: https://orcid.org/0000-0003-1767-5998 | douglaseraldo@mx2.unisc.br

ii Doutora pelo Programa de Pós-Graduação em Comunicação Social da Pontifícia Universidade Católica do Rio Grande do Sul (PUC-RS) e professora adjunta da Universidade de Santa Cruz do Sul. ORCID: https://orcid.org/0000-0003-4792-5716 | fabi@unisc.br
} 
Neste trabalho, partindo das características do narrador pós-moderno e da própria experiência da pós-modernidade (marcada pela fragmentação e por sua complexa relação com o real, dos comportamentos das massas, do espetáculo e do consumo etc.), interpretaremos duas narrativas em videoclipes da banda de $\mathrm{Nu}$ Metal, Disturbed. Em nossa interpretação das narrativas de "Open Yor Eyes" e "Land Of Confusion", construiremos relações intertextuais e refletiremos como os sonhos abortados da revolução erram pelo deserto do real. Todavia, iniciamos nossas reflexões olhando para o narrador pós-moderno e os videoclipes enquanto narrativas.

\section{O NARRADOR PÓS-MODERNO E OS VIDEOCLIPES}

Quando Silviano Santiago se propõe a analisar o narrador pós-moderno, contrastando com a pobreza da experiência e seus impactos na narração levantada por Walter Benjamin, ele está mirando a literatura. Contudo, desconfiamos que suas reflexões, ainda que partindo da leitura literária, são válidas também quanto aos narradores de uma narrativa tipicamente pós-moderna: o videoclipe. O narrador pósmoderno, parece-nos, encontrou nas narrativas dos videoclipes o espaço ideal para narrar, subtraindo-se da ação narrada. Santiago (2019, p. 410) diz que "o narrador pós-moderno é aquele que quer extrair a si da ação narrada, em atitude semelhante à de um repórter ou de um expectador". De acordo com o autor "ele não narra enquanto atuante", pois que "é o movimento de rechaço e distanciamento que torna o narrador pós-moderno" (SANTIAGO, 2019, p. 410).

De acordo com Santiago (2019, p. 411) “o narrador pós-moderno sabe que o real e o autêntico são construções de linguagem". Ademais, lembra que neste processo há por parte do narrador pós-moderno a tentativa de embaralhar as coisas, a ficcionalização, o jornalístico etc. De acordo com ele, “impõe-se a atitude jornalística do narrador diante do personagem, do assunto e do texto. Está ali o narrador para informar o seu leitor do que acontece na plaza" (SANTIAGO, 2019, p. 415). Nisso, Santiago (2019, p. 415) diz ainda que "o narrador se subtrai da ação narrada e, ao fazê-lo, cria um espaço para a ficção dramatizar a experiência de alguém que é observado e muitas vezes desprovido de palavra". Do mesmo modo, lembra que "narrador e leitor se definem como espectadores de uma ação alheia que empolga, emociona e seduz, etc.” (SANTIAGO, 2019, p. 415). 
Para reforçarmos ainda mais o ambiente favorável deste narrador pós-moderno nas narrativas dos videoclipes, podemos lembrar que Silviano Santiago inclusive demonstra como a própria narrativa literária acaba incorporando as influências da televisão, do cinema etc.; diz o autor que,

o espetáculo torna a ação representação. Representação nas suas variantes lúdicas, como futebol, teatro, dança, música popular, etc.; e também nas suas variantes técnicas, como cinema, televisão, palavra impressa etc. Os personagens observados, até então chamados de atuantes, passam a ser atores do grande drama da representação humana. (SANTIAGO, 2019, p. 422)

Se até então nos concentramos um tanto mais nas características do narrador pósmoderno, cremos que podemos nos deter rapidamente na validade dos videoclipes como e enquanto narrativas. Isto, aliás, vem sendo debatido e discutido por pesquisadores e críticos de tal modo que temos uma significativa abordagem e produção sobre o tema.

Nesse sentido, não nos interessa aqui aprofundar a questão, mas reforçar a relevância dos clipes como narrativas populares na pós-modernidade. Para chegarmos a esse estágio, vale dizer que, de acordo com Arlindo Machado (2000, p. 155), foi preciso resolver a questão da sincronização de som e imagem que, segundo o autor, foi resolvida pelo cinema a partir do final da década de 1920. Então é a partir das primeiras experiências nos anos 70, e posteriormente com a popularização do gênero na televisão através do canal MTV, que os videoclipes começam a não apenas popularizarem-se, mas ganhar status. De acordo com Machado (2000, p. 173) “já se foi o tempo em que esse pequeno formato audiovisual era constituído apenas de peças promocionais, produzidas por estrategistas de marketing para vender discos". Partindo disto, o autor nos passa a mensagem de que precisamos prestar atenção nos videoclipes. É uma das nossas intenções neste trabalho.

Diz Machado (2000, p. 173) que o videoclipe cresceu "em ambições, explodiu seus próprios limites e está se impondo rapidamente como uma das formas de expressão artística de maior vitalidade de nosso tempo". O autor ainda relaciona as atitudes transgressivas em videoclipes a bandas que, em seu trabalho, também demonstrem transgressão e independência. "O videoclipe mais interessante é, portanto, aquele que nasce de uma sensibilidade renovada e de uma decisão crítica nos planos musical e audiovisual ao mesmo tempo" (MACHADO, 2000, p. 178). Esse aspecto, aliás, parecenos em perfeita coadunação com os videoclipes interpretados neste artigo, até porque 
encontramos neles "um trabalho menos esclerosado e que se dispõem a colocar entre parênteses à custa do hábito, da repetição ou da imposição do mercado" (MACHADO, 2000, p. 178). Nesse processo de revolução do audiovisual, Arlindo Machado já aponta para o caminho que parece-nos, hoje, predominante nos videoclipes, o grupo que "encara o clipe como uma forma audiovisual plena e autossuficiente, capaz de dar uma resposta mais moderna à busca secular de uma perfeita síntese de imagem e som" (MACHADO, 2000, p. 182). É nesse sentido que,

o clipe já não é algo que necessariamente vem depois da música, tampouco um acessório à música: ele passa a fazer parte do processo de criação. Imagem e som nascem juntos, fazem de uma só e mesma atitude criativa. (MACHADO, 2000, p. 184)

Arlindo Machado, em seu texto, analisa o videoclipe ainda como uma narrativa intimamente ligada à televisão. Hoje, logicamente, o cenário está um tanto diferente com o advento da internet e de plataformas como o YouTube e o Vimeo. "Com o aumento cada vez mais rápido do compartilhamento de diversos conteúdos na rede, seja por parte de amadores, empresas e artistas, a TV perdeu o poder de mostrar videoclipes com exclusividade" (GUEDES \& NICOLAU, 2016, p. 4). Nessa perspectiva, o videoclipe "encontra nos sites de compartilhamento de vídeos um espaço para fortalecer sua produção e veiculação, redefinindo a lógica de circulação e o consumo do público" (GUEDES \& NICOLAU, 2016, p. 4). Na verdade, podemos observar que, com as mudanças sofridas no mercado fonográfico, que dentre outras coisas substituiu o lançamento de álbuns por singles, o planejamento, produção e publicação de videoclipes nas plataformas digitais, especialmente o YouTube, tornou-se uma imposição.

Aliás, isso confere aos vídeos também a natureza de narrativas de alcance de massa. Por exemplo, na elaboração deste trabalho, o videoclipe de "Land of confusion" contava com mais de 60 milhões de visualizações no YouTube. “Open your eyes” com mais de 11 milhões de visualizações; e contando novas visualizações.

Portanto, tanto pela evolução dos aspectos técnicos, culturais e narrativos; tanto pela relevância, impacto, influência e alcance dos videoclipes, mais do que analisar, precisamos nos dedicar à "intepretação" destas narrativas que avançam e mudam em sua técnica. É o que pretendemos na próxima seção ao tratarmos dos videoclipes propostos. 


\section{ABRA SEUS OLHOS! FAÇA A REVOLUÇÃO!}

Figura 1: Referência ao icônico cartaz do Tio Sam reforça a incitação

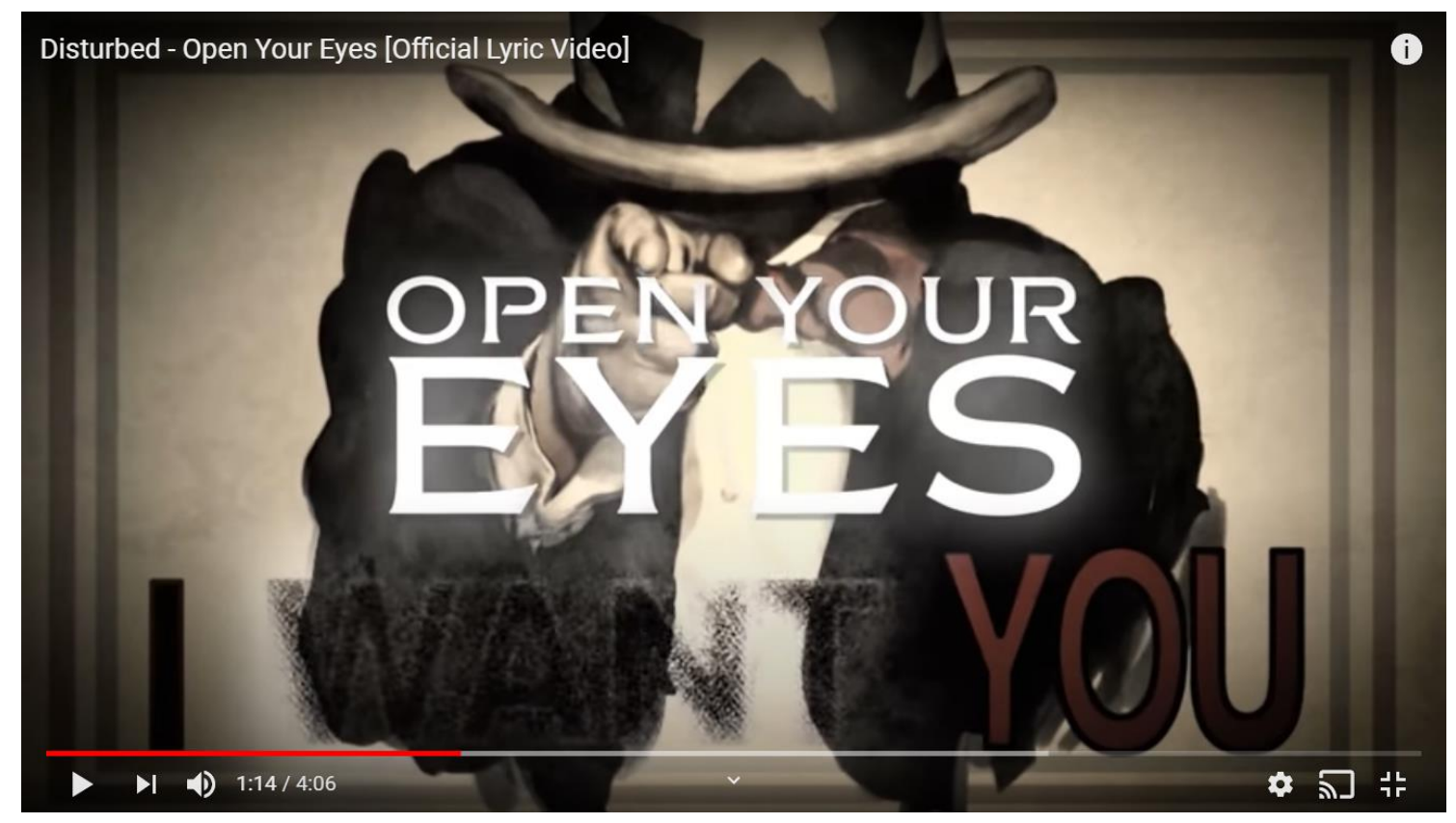

Fonte: Youtube

Publicado no YouTube em 1 de setembro de 2016, o videoclipe de "Open your eyes" apresenta uma das características contemporâneas que se tornou tendência nos videoclipes, o lyric vídeo, quando a letra da canção é incorporada às imagens e ao som. Nesse caso específico parece-nos que a escolha se torna ainda mais potente pelo uso da segunda pessoa, o que confere e reforça quase que um grito de desespero da narração: abra seus olhos! Mais que um convite, o conjunto soa como que uma incitação. A seu modo, é como se a narrativa tal como quando Morpheus oferece a Neo em Matrix (1999) a escolha entre a pílula azul e a vermelha. Em ambos os casos, um chamado ao real desertificado de uma sociedade pós-moderna sob a égide dos simulacros, do hiper-real e da cibercultura. "Discern from what's fiction and what is true" confirma a letra da canção, e exposta no vídeo (DISTURBED, 2016). 
Figura 2: Disturbed, abra seus olhos!

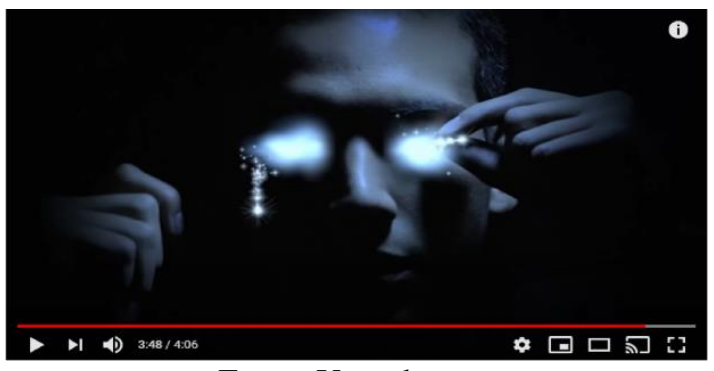

Fonte: Youtube.
Figura 3: Estou te oferecendo a verdade, nada mais!

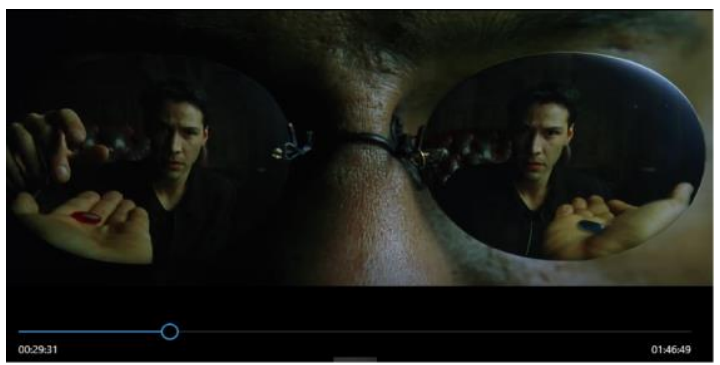

Fonte: Filme Matrix.

Quando Morpheus em Matrix depois de Neo ter optado pela pílula vermelha e assim ficar no "Mundo de Alice", decidido a seguir até a "toca do coelho" e encontrar uma Chicago pós-guerra global que levou ao domínio das máquinas, ele diz a já célebre frase: "Bem-vindo ao deserto do real" (MATRIX, 1999). O termo remete a Jean Baudrillard, instituindo talvez a visão mais radical sobre a relação da sociedade pósmoderna com a realidade. A era dos simulacros, das simulações, do hiper-real, "a simulação já não é a simulação de um território, de um ser referencial, de uma substância. É a geração pelos modelos de um real sem origem nem realidade: hiper-real" (BAUDRILLARD, 1991, p. 8). Isso abre espaço para debatermos o que Slavoj Zizek vem a chamar de paixão pelo real como marca deste século XX:

O momento último e definidor do século XX foi a experiência direta do Real como oposição à realidade social diária - o Real em sua violência extrema como preço a ser pago pela retirada das camadas enganadoras da realidade. (ZIZEK, 2002, p. 19)

Todavia, para Zizek (2002, p. 23), há um paradoxo fundamental nessa paixão pelo real que "culmina no seu oposto aparente, num espetáculo teatral". De acordo com o autor,

\footnotetext{
A Realidade Virtual simplesmente generaliza este processo de oferecer um produto esvaziado de sua substância: oferece a própria realidade esvaziada de sua substância, do núcleo duro resistente do Real - assim o café descafeinado tem o aroma e o gosto do café de verdade sem ser o café de verdade, a Realidade Virtual é sentida como a realidade sem o ser. Mas o que acontece no final desse processo de virtualização é que começamos a sentir a própria "realidade real" como uma entidade virtual (ZIZEK, 2002, p. 25)
} 
E aqui podemos retornar ao videoclipe de "Open your eyes". Parece-nos plausível considerar o sujeito na narrativa como uma metáfora alegórica de uma sociedade, "You would all be runnin"” (DISTURBED, 2016), a que a "realidade real" passa a ser percebida como uma entidade virtual. Notemos que o sujeito-personagem-protagonista do videoclipe não passa de um vulto cuja identidade está envolta por sombras. De olhos fechados, é tipicamente um sujeito do pós-moderno em que ainda ressoa, inclusive, os ecos da indústria cultural de Adorno. Tal vulto é hipnotizado pela cultura e todas as suas "crias", como a cibercultura, as mídias etc. Um sujeito imerso em um cenário surreal controlado pela técnica. É a este vulto que a narração parece incitar. Abra seus olhos! Liberte-se da paralisia. A seu modo, o videoclipe parece um chamado a este vulto, como se fosse "uma intervenção mais violenta para [sacudi-lo] do entorpecimento ideológico, do estado hipnótico consumista..." (ZIZEK, 2002, p. 23).

O videoclipe de "Open your eyes" não é o único da Disturbed a demonstrar este desconforto com a pós-modernidade e tratar com desconfiança não apenas a realidade, mas de que modo esta está manipulada pelas elites culturais, econômicas e midiáticas. Vemos isso em "The vengeful one" e também em "Land of confusion", que discutiremos um pouco mais neste trabalho.

Diferentemente de "Open your eyes", em que temos o uso dos efeitos visuais digitais, "Land of confusion" (2009), no videoclipe da Disturbed, opta-se pela animação, sendo dirigido por Terry Fitzgerald e Todd McFarlane, este último com direções de videoclipes usando a mesma estética da animação para bandas como Pearl Jam e Korn.

Em "Land of confusion", percebemos uma narrativa linear bastante comum, tradicional, iniciada com a chegada à terra de The Guy, mascote da banda, o mesmo que no videoclipe de "The vengeful one" é considerado um Messias das Trevas; com esta chegada, a chegada de um herói capaz de despertar as massas de sua imobilidade. 
Figura 4: The Guy encarnando a figura de um messias sombrio e com sorriso de Cheshire

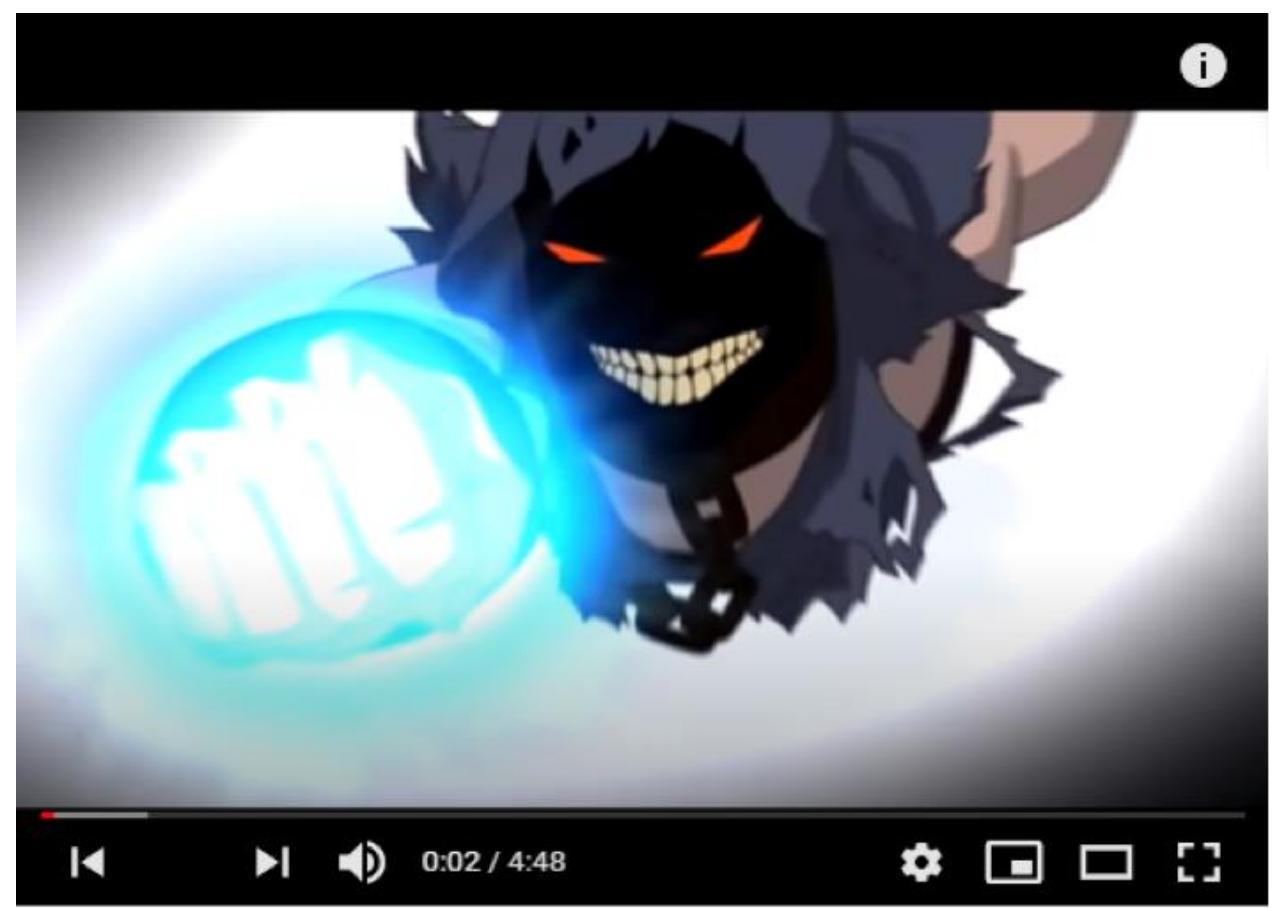

Fonte: Youtube.

Isso porque a revolução que parece desejar desencadear o protagonista do videoclipe é a insurreição contra o controle e a manipulação dessas massas. $\mathrm{Na}$ perspectiva da narrativa há um conglomerado global a oprimir e controlar tais massas por meio do poder político, bélico e, especialmente, financeiro. As referências ao capitalismo são explícitas a partir do homem gordo, barrigudo, um balão cheio de dinheiro. Não à toa o audiovisual é uma produção ainda nas ondas reverberantes da crise financeira - e global - de 2008; também às portas de movimentos como o Ocuppy Wall Street. O capitalismo, no videoclipe, é notadamente o titereiro a manipular as potências globais em estado de confusão. Em determinado momento da narrativa, inclusive há uma explosão de dólares voando pelo céu da metrópole. Redistribuição da renda enquanto processo metafórico.

A esse contexto de desigualdade social, econômica e de controle das massas é que o personagem-protagonista pretende se opor. Encarna assim a perspectiva do messias que salvará o povo; que os liderará contra esse poder global e financeiro mesmo que para tal tenha de aderir à violência revolucionária. Nessa perspectiva, Zizek nos aponta mais alguns caminhos. Partindo da leitura da dialética imobilizada de Walter Benjamin, o autor reflete que "na expectativa do evento Messiânico, a vida se imobiliza" (ZIZEK, 2002, p. 23). 

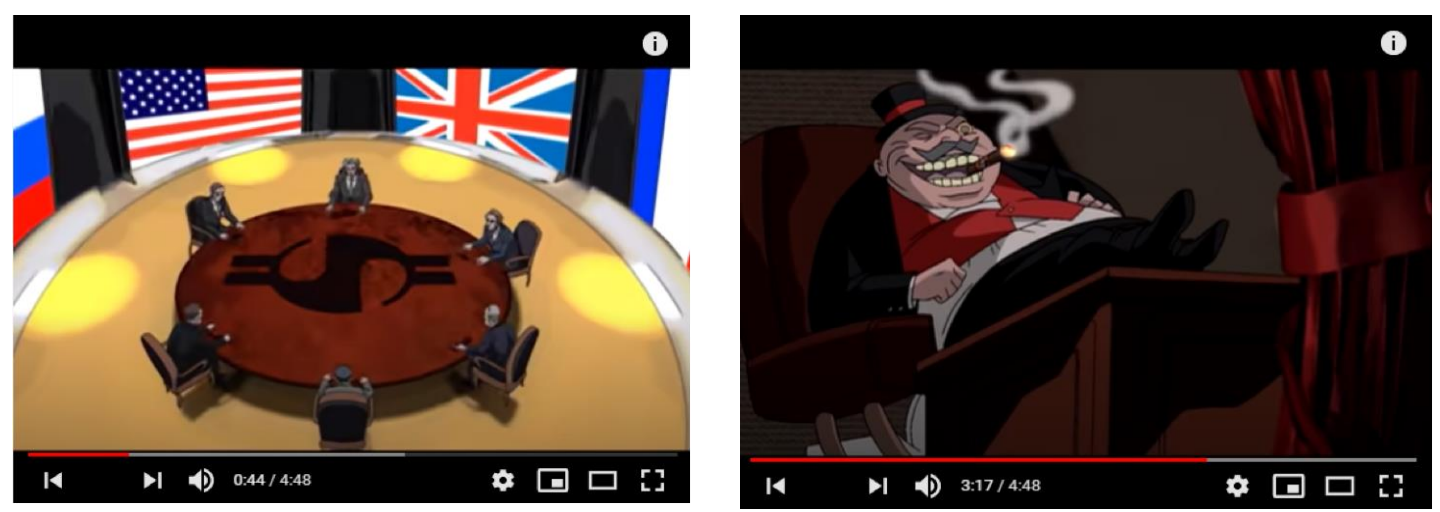

Figuras 5, 6 e 7: Land of confusion

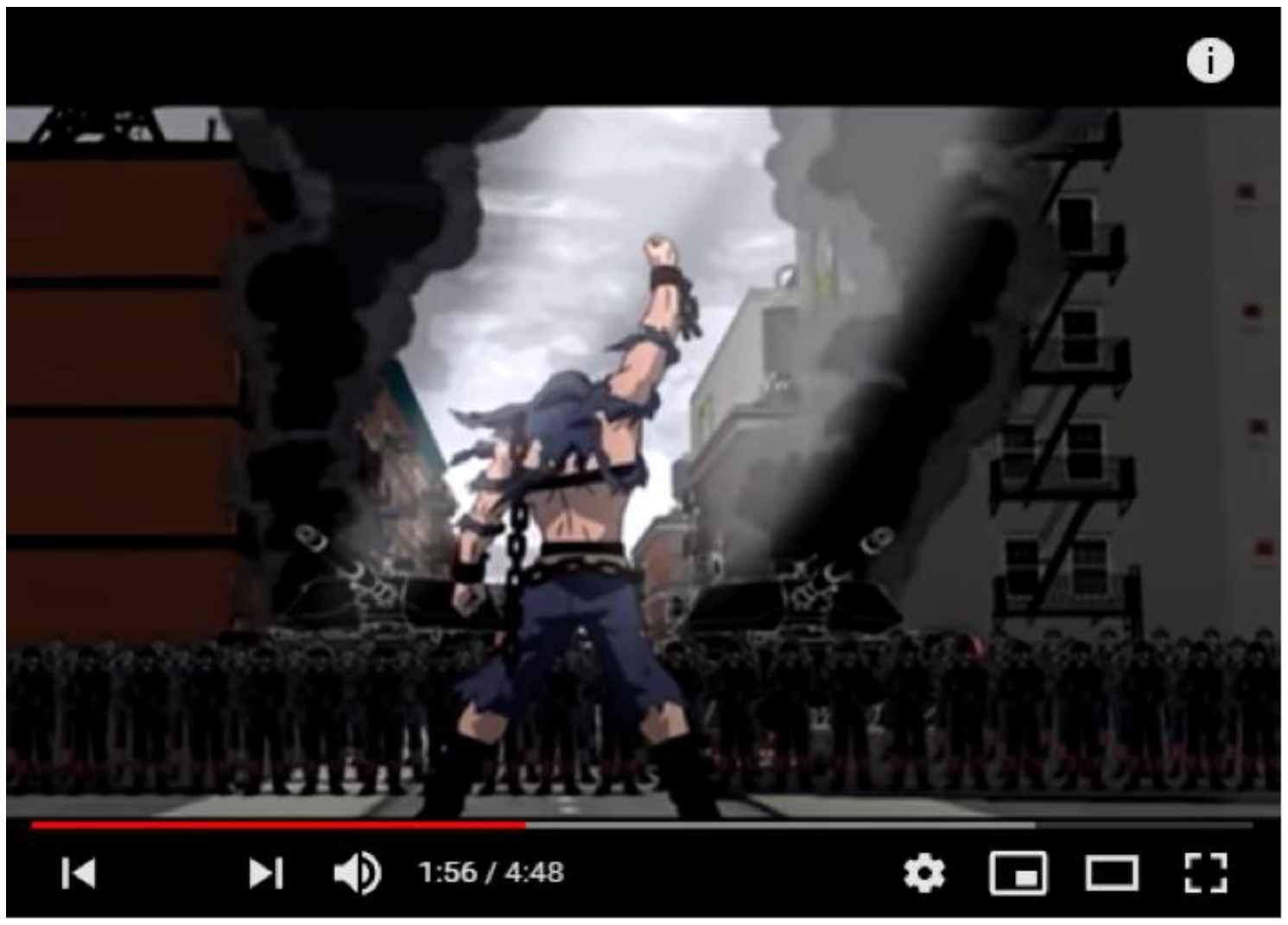

Fonte: YouTube.

Nisso talvez a contradição da própria narrativa do videoclipe. Observando a experiência da Revolução Cubana, Zizek (2002, p. 21) aponta que "o principal resultado da revolução é reduzir a dinâmica social à imobilidade". Tudo bem que no caso da narrativa deste videoclipe não se haja uma perspectiva do pós-revolução, mas da própria revolução instada pelo messias. Um chamado à catarse coletiva. Um abrir de olhos, um 
quebrar de correntes, como propõe a animação. Nesse processo, justamente a violência como conquistadora de direitos dos que o videoclipe concebe como os oprimidos pelo sistema. Logicamente, nessa liberação da violência, certa adesão fundamentalista, talvez por não ser mais "possível acordá-las [as massas] com os meios comuns da elevação da consciência e da educação" (ZIZEK, 2002, p. 23). Falhando, portanto, tais meios, como no clipe, voltamos sempre à violência como última instância ou possibilidade. Ao menos é o que temos no transcorrer do videoclipe de "Land of confusion".

Figura 8: O povo segue seu líder

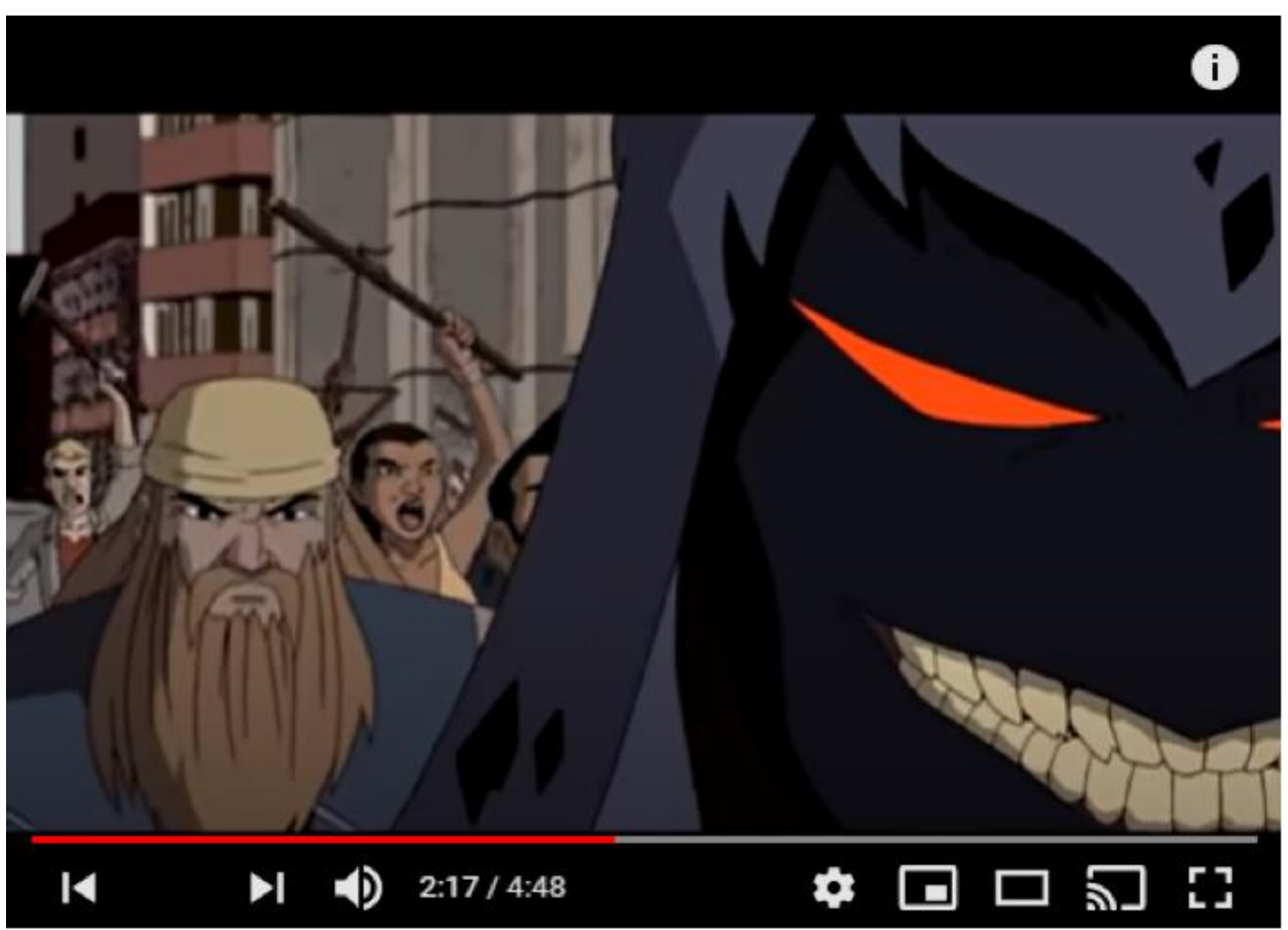

Fonte: YouTube.

No clipe observamos o romper desta imobilidade; marcado pela utopia da revolução; The Guy, o messias, lidera o povo que sai dos subsolos, de seus esconderijos, de seus edifícios, partindo para o enfrentamento das forças opressoras desta elite que controla e presumidamente "cria" o próprio real a sua maneira e de acordo com suas vontades. Talvez o reforço paradoxal e denunciante da imobilidade das massas planetárias. 
Determinadas visões do pós-moderno observam-no de certo modo aprisionado à utopia revolucionária. Ele tenta ainda entender as revoluções no modernismo enquanto segue sonhando com suas próprias revoluções, Maio de 1968, contracultura, hippies e mesmo contemporaneamente os ocuppys e as primaveras. Um desejo que parece não cessar; e a cultura como prova disso. No desconfiar de tudo, especialmente da própria realidade, o pós-moderno vive o sonho permanente da revolução. Parece-nos que o videoclipe de "Land of confusion" pode ser exemplo disso, como o é também o recente filme do Coringa (2019) dirigido por Todd Phillips.

O personagem originalmente criado nos quadrinhos, nesse filme é trazido de uma forma mais "realística”. Entre o louco e a vítima de uma sociedade cruel, cada vez mais desumana e degradada, o vilão então assume às vezes o papel do herói. Um anti-herói na perspectiva de muitos espectadores. Se no videoclipe da Disturbed, The Guy chega como um cometa salvador; em Coringa, o messias vai surgindo silenciosamente a cada pancada que o mundo lhe dá. Contudo, se nas duas narrativas o messianismo começa de formas distintas, o desfecho de ambos é muito semelhante. A promessa da revolução. $O$ abrir dos olhos. O tirar as massas de sua imobilidade de modo que, ao final do filme, temos hordas de palhaços solidários a se erigir contra o sistema. Como método de rompimento desta imobilidade sempre o irromper catártico da violência. A promessa de regeneração, como vemos no videoclipe quando as imagens das cidades destruídas retrocedem a um estado anterior, puro; ou então com o status de verdade e realidade dita pelo Coringa após atirar contra a cabeça do apresentador de Talk Show, "Boa noite! Lembrem-se, a vida é um merda!" 
Figura 9: Quem diria, o palhaço lidera a revolução

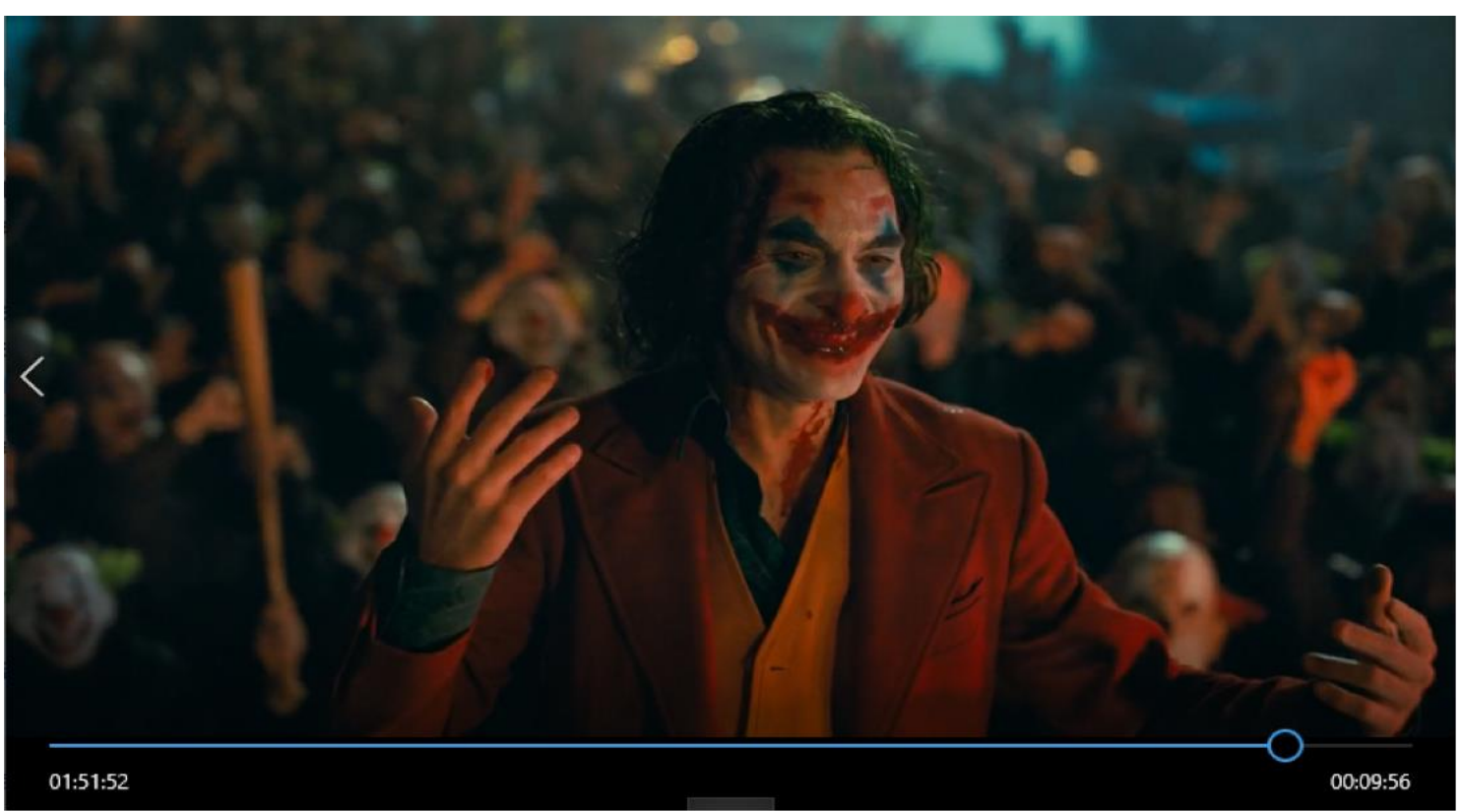

Fonte: Filme Coringa.

Todavia, é preciso observar a explosão de violência tanto no videoclipe quanto no filme enquanto sintoma, um "mecanismo de defesa que cobre o vazio da incapacidade de intervir eficazmente na crise social" (ZIZEK, 2002, p.38). Ainda de acordo com Zizek:

\footnotetext{
Noutras palavras, a própria fúria dos pogroms antissemitas é uma prova $a$ contrario da possibilidade autêntica de revolução proletária: sua energia excessiva só pode ser entendida como uma reação do reconhecimento ("inconsciente") da oportunidade perdida. (ZIZEK, 2002, p. 38)
}

Perguntamo-nos se não é também, ao seu modo, o que vemos nos videoclipes e filmes aqui discutidos. Todos eles marcados pela excessiva paixão pelo real da qual fala Zizek, pois, de acordo com o autor, o núcleo desta paixão “é essa identificação com o gesto heroico de assumir - integralmente a obscenidade suja do outro lado do poder: a atitude heroica de alguém que tem de fazer o trabalho sujo" (ZIZEK, 2002, p. 45). E é aí que nos parece que os videoclipes estudados neste artigo trazem os paradoxos e contradições da utopia revolucionária pós-moderna. Parecem insistir numa ilusão e, aprisionados em sua busca pelo real. Para enfrentar tais contradições e paradoxos, talvez a necessidade de considerar o que diz Slavoj Zizek: 
(...) devemos opor a paixão reacionária à progressista pelo Real: enquanto a reacionária é o endosso do reverso obsceno da lei, a "progressista" é a confrontação com o Real do antagonismo negado pela "paixão da purificação", que - em suas duas versões, a de esquerda e a de direita - parte de que o Real é tocado na, e através da, destruição do elemento excessivo que introduz o antagonismo. Devemos aqui abandonar a metáfora padrão do Real como a Coisa aterradora que não se é capaz de enfrentar cara a cara, como o Real definitivo oculto sob camadas de véus imaginários e/ou simbólicos: a própria ideia de que sob a aparência enganadora oculta-se uma Coisa Real definitiva a Coisa Real é um espectro fantasmático cuja presença garante consistência de nosso edifício simbólico, permitindo-nos evitar sua inconsistência constitutiva ("antagonismo"). (ZIZEK, 2002, p. 46-7)

É nesse sentido que parece-nos que os videoclipes aqui discutidos em sua incitação ao abrir dos olhos, ainda estão fortemente marcados por tal espectro fantasmático da Coisa Real. Ademais, o próprio sonho utópico da revolução parece habitar fronteiras nem sempre claras entre o revolucionário e o reacionário. Os limites são tênues e muitas vezes, não raro, livres de má "intepretação" por espectadores, leitores etc.

\section{REFLEXÕES FINAIS}

No decurso desse trabalho, partimos do narrador pós-moderno e dos videoclipes e sua consolidação enquanto arte audiovisual deste pós-moderno para nos determos então na interpretação de duas narrativas em videoclipes. "Open your eyes" e "Land of confusion", ambos da banda Disturbed. Não nos privamos de construir relações destes com outras obras, especialmente no cinema. Nesta construção, não apenas compreendemos as narrativas dos videoclipes dentro de seu contexto pós-moderno como também nos dedicamos a tentar compreender suas contradições e paradoxos. Especialmente como elas refletem a paixão pelo real, tão caracterizante desse pósmoderno com que nelas está entranhado o sonho, a utopia da revolução. Um sonho que parece justamente errar pelo deserto do real.

Nesse sentido, a insistência na construção de narrativas que clamam por uma revolução e pelo desvelar de um Real Escondido sob camadas de manipulação e controle, de certo modo, apontam também para a melancolia das revoluções perdidas. É como se a cada narrativa, do clipe de 2009 ao de 2016 ou ao filme do Coringa (2019), nos déssemos conta de que estamos constantemente perdendo aquilo que Lukács chamou de “Augenblick (o momento quando, por pouco tempo, há a abertura para um ato de 
intervenção numa situação)", que no caso "é a capacidade de aproveitar o momento certo, agravando o conflito antes que o Sistema possa acomodar a demanda" (ZIZEK, 2003, p. 171).

Por conseguinte, podemos nos perguntar ainda quanto ao próprio paradoxo de tais narrativas de, ao cabo, não se tornarem ou serem meros agentes desta imobilidade social? Vejamos que, no caso dos videoclipes, seus alcances atingem uma massa. Massa global, inclusive. Milhões de pessoas, de espectadores. Todavia, se em ambas as narrativas temos a incitação, mais explícita no caso de "Open your eyes", ou implícita, caso de "Land of confusion", à revolução, ao sair da imobilidade, no final de tudo temos o quê? Não sofrem elas também da ostalgia? Em suas procuras pela Coisa real, não são talvez exemplos dessa imobilidade que não apenas aguarda por um messias, mas que também procura por um mundo que poderia ter sido?

E, se apontamos aqui as contradições e paradoxos presentes nestes videoclipes, não o fazemos em demérito. Pelo contrário. A possibilidade da construção de interpretações acerca das narrativas que essa arte visual nos traz é a forma de valorizá-la e pô-la em pé de igualdade com outras formas narrativas. É preciso considerar a relevância, o papel e o alcance que tais narrativas obtiveram em nosso contemporâneo. Uma cultura de massa se considerarmos as casas decimais de suas visualizações. E ao passo que as interpretamos, talvez a construção de um caminho crítico para que elas cada vez mais evitem ser agentes de imobilidade social, de distração e que possam aparecer em todo seu potencial reflexivo e de recolhimento.

\section{Referências}

CORINGA. Direção de Todd Phillips. Estados Unidos: Village Roadshow Pictures/DC Films, 2019. 122min.

DISTURBED. Land of confusion. YouTube. Disponível em: https://www.youtube.com/watch?v=YV4oYkIeGJc\&list=RDMMYV4oYkIeGJc\&index $=1$. Acesso em: 17 de outubro de 2020 .

Open your eyes [Official Lyric Video]. YouTube. Disponível em: https://www.youtube.com/watch?v=9cNpKRXwaj4\&list=RD9cNpKRXwaj4\&index=1. Acesso em: 17 de outubro de 2020. 
GUEDES, Fabrícia; NICOLAU, Marcos. Os Videoclipes Interativos e a Apropriação dos Usuários para Compartilhamento no YouTube. XVIII Congresso de Ciências da Comunicação na Região Nordeste - Caruaru - PE, 2016.

MACHADO, Arlindo. A televisão levada a sério. São Paulo: Editora Senac, 2000.

MATRIX. Direção de Lilly Wachowski e Lana Wachowski. Estados Unidos: Village Roadshow Pictures, 1999. 136min

SANTIAGO, Silviano. O narrador pós-moderno. In: SANTIAGO, Silviano. 35 Ensaios de Silviano Santiago. Seleção e introdução de Ítalo Moriconi. São Paulo: Companhia das Letras, 2019. 409-422pp.

ZIZEK, Slavoj. Bem-vindo ao deserto do Real. São Paulo: Boitempo, 2002.

De história e Consciência de Classe a Dialética do Esclarecimento, e Volta. In: Lua Nova: Revista de Cultura e Política, São Paulo, 2003. p. 159-176.

Recebido em: 14/06/2021

Aceito em: 29/07/2021 